\title{
MENGUNGKAP SOSOK DAN SEPAK TERJANG TOKOH LEGENDARIS LA KOKULI MELALUI ANALISIS SIMBOLIK TERHADAP GELARNYA: KAMBERA KAKUNI
}

\author{
Oleh : Aderlaepe \\ Dosen Jurusan Pendidikan Bahasa Inggris FKIP UHO \\ Email: aderlaepe@uho.ac.id
}

\begin{abstract}
Abstrak. This research investigates a mysterious figure and his roles in the society of Siua Liwuno 'nine villages', a territorial of Munanese kingdom long ago. He was La Kokuli, lived in Watuputih villages and his social tittle was Kambera Kakuni 'yellow butterfly'. His social tittle is a gate to analyze who was he and what was his roles in the society since there is no written reference about him as the impact of Munanese people as an illiterate society long ago. Through semioticly analysis, he was a sufi 'islamic metaphysicsm' who acquainted Islam in the society of siua liwuno 'nine villages' Muna in the $17^{\text {th }}$ century. Kambera Kakuni 'yellow butterfly' is a symbol of Tarekat Naksabandiah, one of Islam metaphysic doctrin. He came from Aceh, as the pupil of Syech Abdul Rauf Singkil (Syech Tengku Syiah Kuala).
\end{abstract}

Key Words: La Kokuli, Kambera Kakuni, Siua Liwuno, Syech Tengku Syiah Kuala, and Watuputih

\section{A. PENDAHULUAN}

Nama La Kokuli tidak asing bagi masyarakat Watuputih (saat ini menjadi Kecamatan Watopute) di Kabupaten Muna Sulawesi Tenggara. Beliau adalah tokoh kharismatis pada zamannya dan merupakan salah satu leluhur kebanggaan bagi masyarakat Watuputih. Beliau bergelar Kambera Kakuni yang secara harfiah berarti 'kupu-kupu kuning'.

Tidak ada catatan tertulis yang memberikan informasi mengenai asal-usul La Kokuli. Apakah beliau lahir di Watuputih sebagai orang lokal (indigenous people), atau pendatang yang berasal dari daerah lain. Demikian pula halnya dengan sepak terjangnya dalam masyarakat Watuputih pada khususnya dan masyarakat Muna pada umumnya, tidak diketahui sama sekali akibat tidak adanya catatan tertulis. Satusatunya petunjuk yang memberikan informasi mengenai identitas beliau adalah kuburannya yang bercorak Islam karena adanya batu nisan. Kuburan beliau ada di Watuputih, tepatnya di puncak bukit Harimau Kontu, sekitar $5 \mathrm{~km}$ dari Raha (Ibu Kota Kabupaten Muna). Puncak ini disebut juga bukit La Kokuli karena di sanalah kuburan beliau. Pada saat ini, puncak tersebut menjadi objek wisata pegunungan dengan nama puncak BALADEWA (barisan bukit La Kokuli, Wa Kofointo, dan Wa Sirikamba).

Masyarakat setempat menganggap bahwa kawasan perbukitan yang berjejer dari arah timur ke barat, yaitu bukit La Kokuli, Wa 
Kofointo, dan Wa Sirikamba adalah tempat keramat yang dihuni oleh mahluk jahat (iblis, syaitan, dan jin). Ini adalah salah satu bentuk kearifan lokal masyarakat untuk menjaga kelestarian alam dan lingkungan, dengan maksud agar kawasan perbukitan tersebut tidak diganggu oleh masyarakat setempat; tidak dijadikan sebagai areal perladangan. Pada penghujung tahun 2017 para pemuda Watuputih mengkreasi kawasan ini sebagai tempat wisata dengan ikon "negeri kayangan para leluhur". Mereka membentuk wadah organisasi sosial bernama SEROJA MERAH (Sekelompok Remaja Merangkai Alam Hayati). Beberapa potensi wisata di kawasan ini mereka observasi dan mereka kemas sebagai daya tarik bagi wisatawan, antara lain: (1) pepohonan yang rindang di kawasan puncak dan sekitarnya, (2) pemandangan sunset di waktu sore sekaligus sunrise di waktu pagi, (3) telaga air di puncak, (4) batu berbentuk harimau yang dinamakan harimau kontu, (5) kuburan La Kokuli yang diyakini sebagai wali Allah sehingga dapat mendatangkan karomah bagi pengunjungnya, (6) keanekaragaman tumbuhan yang menyediakan objek penelitian bagi akademisi, dan (7) panorama pegunungan yang menawan dengan udaranya yang sejuk.

Adanya batu nisan pada kuburan La Kokuli menandakan bahwa beliau adalah seorang Muslim. Kuburan ini telah dipugar secara sederhana oleh masyarakat Watuputih pada awal tahun 200an, yang disponsori oleh Almarhum Drs. Suhadar Silangi. Hingga saat ini La Kokuli masih merupakan sosok yang misterius, tidak ada satu pun tetua yang mengetahui dan memastikan siapa nama aslinya, dari mana asal-usulnya (apakah orang lokal atau pendatang yang datang ke Muna dengan maksud tertentu), bagaimana sepak terjangnya dalam masyarakat, termasuk ia hidup pada abad berapa. Tidak ada referensi tertulis yang memberikan informasi mengenai semua ini. Hal ini merupakan akibat dari corak masyarakat Muna pada zaman dahulu (sebelum abad $\mathrm{XX}$ ) yang niraksara atau tidak beraksara (illiterate society). Sebagai masyarakat niraksara, hasil-hasil kebudayaan tidak didokumentasikan secara tertulis. Satusatunya media yang digunakan untuk mendokumentasikan hasil-hasil kebudayaan bagi masyarakat niraksara adalah tradisi lisan (Rahman, 1999:viii). Tradisi lisan adalah wacana yang dituturkan dalam masyarakat dan disampaikan atau diwariskan secara turun temurun melalui lisan (Lord, 1995:1; Pudentia, 2010). Tradisi lisan dapat berupa cerita lisan, lukisan, atau gerak (tarian atau upacara ritual).

Tulisan ini mengulas sosok La Kokuli dan sepak terjangnya dalam 
masyarakat Watuputih pada khususnya dan masyarakat siua liwuno 'sembilan kampung' pada umumnya serta masyarakat Muna melalui gerbang semiotika. Siua liwuno 'sembilan kampung' merupakan salah satu wilayah teritorial Kerajaan Muna yang terdiri atas Lohia, Mantobua, Duruka, Kondongia, Mabodo, Dopi, Bungi, Watuputih, dan Lambiku. Siapa La Kokuli dan apa sepak terjangnya yang fundamental dalam masyarakat siua liwuno 'sembilan kampung' pada khususnya dan masyarakat Muna pada umumnya? Pintu masuk untuk menelusuri sosok La Kokuli dan sepak terjangnya melalui gelarnya, yaitu kambera kakuni 'kupu-kupu kuning'. Pendekatan yang digunakan adalah semiotika dan teknik analisis yang digunakan adalah sistem interpretasi semiotik. Data primer bersumber dari tuturan lisan yang diwariskan secara turun-temurun (tradisi lisan) dan situs atau peninggalan beliau. Data sekunder berupa referensi terkait untuk menemukan mata rantai/kesinambungan informasi mengenai sosok La Kokuli dan sepak terjangnya.

\section{B. METODE PENELITIAN}

Penelitian ini didesain secara deskriptif kualitatif. Data berupa tuturan lisan yang diwariskan secara turun temurun mengenai latar belakang kehidupan La Kokuli dikumpulkan melalui informan. Dalam kaitan ini, informan yang digunakan merupakan story teller 'pencerita kisah'. Kisah-kisah kehidupan La Kokuli yang dikumpulkan dari story teller 'pencerita kisah' merupakan data dan bahan penguat argumentasi dalam melakukan analisis secara simbolik terhadap gelarnya yaitu kambera kakuni 'kupu-kupu kuning'. Analisis secara simbolik yang dimaksud adalah analisis semiotika dengan menerapkan teknik dan sistem interpretasi secara semiotik yang diperkenalkan oleh Pierce (1965).

Gelar kambera kakuni 'kupu-kupu kuning' merupakan gelar simbolik yang mencerminkan sosok dan sepak terjang La Kokuli. Dalam pandangan semiotika komunikasi yang diperkenalkan oleh Pierce (1965), ekspresi simbolik digunakan untuk mengkomunikasikan sesuatu. Sebagai ekspresi simbolik, pemaknaan dan penafsirannya dilakukan melalui proses semiotis secara totalitas. Hoed (2014:33) menegaskan bahwa proses semiosis dalam pemaknaan dan penafsiran terhadap simbol dikaitkan dengan konteksnya. Interpretasi simbol melalui proses semiosis ini menerapkan Segi Tiga Pierce (Pierce Triangle), yang memaknai simbol melalui tiga tahap. Pertama melalui panca indera (representamen). Kedua mengaitkan representamen dengan pengalaman dan kognisi manusia yang memaknai representamen, yakni objek. Ketiga menafsirkan objek sesuai dengan 
pengalaman dan pengetahuan (Hoed, 2014:32).

\section{HASIL DAN PEMBAHASAN}

\section{Sosok La Kokuli Dilihat dari Gelarnya}

Tidak adanya sumber informasi tertulis mengenai La Kokuli menginspirasi penulis untuk melakukan kajian berdasarkan gelarnya, yaitu Kambera Kakuni 'kupu-kupu kuning'. Aswat Hanafi, Ketua Seroja Merah, yang mengadopsi pendapat Alimuddin menyatakan bahwa La Kokuli seorang pendatang berkebangsaan Cina. Nama aslinya Kho Khu Lee. Oleh masyarakat Watuputih, penyebutannya disesuaikan dengan cara penyebutan setempat yang dipengaruhi oleh bahasa Muna, sehingga menjadi La Kokuli. Ini dibuktikan dengan adanya piring klasik bertuliskan aksara Cina, ditemukan di kaki bukit Wa Kofointo, sekitar 200 m dari puncak bukit Harimau Kontu. Selanjutnya Aswat Hanafi menjelaskan bahwa La Kokuli semasa hidupnya memimpin perlawanan dan pengusiran terhadap para perompak/bajak laut di Selat Buton yang meresahkan masyarakat Muna. Ia berhasil membebaskan masyarakat Muna dari ancaman para perompak yang merampas harta secara paksa, bahkan memperkosa dan menculik para gadis.

La Ode Sirad Imbo (dalam wawancara tanggal 22 Agustus 2015) menuturkan bahwa tokoh yang berjasa menumpas bajak laut di Siua Liwuno (Negeri Sembilan) adalah Ade Sungku Sara. Siu Liwuno pada zaman kerajaan meliputih sembilan kampung, yaitu Lohia, Mantobua, Duruka, Kondongia, Mabholu, Dopi, Watopute, Lambiku, dan Dana. Ade Sungku Sara bersama masyarakat di Siua Liwuno membangun benteng dari batu di Lasunapa. Pada tahun 1916, benteng itu dibongkar atas perintah Belanda dan batunya digunakan sebagai material jalan pelabuhan Raha (saat ini Ibu Kot Kabupaten Muna). Menurut La Ode Sirad Imbo, atas jasanya itu Ade Sungku Sara dan keturunannya seharusnya diberi kehormatan tersendiri.

La Kokuli dan Ade Sungku Sara tentu saja sosok yang berbeda. Mereka hidup di abad yang berbeda. Ade Sungku Sara hidup pada abad ke -19, sedangkan La Kokuli jauh sebelum itu. Keduanya layak dianggap sebagai pahlawan atas jasanya mengusir bajak laut yang senantiasa merampok masyarakat Muna.

Menurut tradisi lisan masyarakat Watuputih, La Kokuli adalah sosok yang memiliki ilmu kekebalan. Badannya tidak ditembusi benda tajam berupa keris, pedang, atau pun tombak. Oleh karena itu ia diberi nama La Kokuli ( $\mathrm{La}$ adalah penanda gender laki-laki bagi masyarakat Muna, sedangkan kokuli adalah bahasa Muna yang berarti "berbadan kebal"). Ini berarti bahwa La Kokuli bukan nama asli, tetapi nama yang diberikan oleh 
masyarakat setempat. Karena ia memiliki ilmu kebal, maka masyarakat setempat menyebutnya La Kokuli 'orang yang kebal'. Jadi bagi masyarakat Watuputih, nama asli La Kokuli bukan Kho Khu Lee.

Selanjutnya yang menjadi pertanyaan menarik adalah mengapa versi Alimuddin yang diadopsi oleh Aswat Hanafi berbeda dengan versi tradisi lisan masyarakat Watuputih? Jawabannya begitulah tradisi lisan. Salah satu ciri khas tradisi lisan adalah adanya variasi atau perbedaan versi mengenai sesuatu hal atau objek antara kelompok masyarakat yang satu dengan kelompok masyarakat lainnya dalam satu komunitas. Tradisi lisan sama halnya dengan folklor, diwariskan dan disebarluaskan secara turun temurun melalui penuturan lisan, sehingga terdapat berbagai versi atau variasi (Danandjaja, 1997: 141). Tradisi lisan hanya mengandalkan ingatan yang terpola dalam memori dan diwujudkan melalui aktivitas kelisanan (Ong, 1982: 34). Daya ingat manusia berbeda-beda sehingga menuturkan cerita ada yang utuh, ada juga yang tidak utuh bahkan berbeda.

Pertanyaan menarik berikutnya adalah dari kedua versi di atas, mana yang lebih mendekati kebenaran? Apakah La Kokuli nama aslinya Kho Khu Lee atau bukan? Di sini penulis tidak memberi penilaian pada kedua versi tersebut dan tidak mengklaim versi mana yang lebih mendekati kebenaran. Dalam tulisan ini, penulis menampilkan ulasan ilmiah dari gelarnya, bukan namanya. Gelarnya kambera kakuni 'kupu-upu kuning' dapat dijadikan sebagai gerbang untuk menelusuri lebih jauh siapa dia, bagaimana sepak terjangnya, sekaligus asal-usulnya.

Pada dasarnya pemberian gelar kepada seseorang didasari oleh ketokohan orang tersebut dalam masyarakat. Dalam masyarakat Muna gelar yang diberikan kepada seseorang merefleksikan strata sosialnya. Gelar dalam masyarakat Muna adalah: (1) Sangia dan Omputo khusus untuk Raja, (2) Aro dan Pata untuk golongan Каоти, (3) Мапи untuk golongan Walaka, dan (4) Ma untuk golongan Maradika dan Kodasano. Akan tetapi, gelar yang disandang oleh La Kokuli yakni Kambera Kakuni 'kupu-kupu kuning' tidak mencirikan gelar anggota masyarakat Muna. Ini berarti bahwa gelar Kambera Kakuni 'kupu-kupu kuning' tidak diberikan oleh masyarakat Muna (masyarakat Watuputih), sekaligus menandakan bahwa ia bukan anggota masyarakat Muna, tetapi sebagai pendatang.

Kambera Kakuni 'kupu-kupu kuning' adalah lambang tarekat Naqsyabandiah. Tarekat ini didirikan oleh Buhauddin AnNaqsyabandi, lahir di Bukhara Uzbekistan pada abad ke -14 M. Dari sekian banyak tarekat yang ada (lebih seratus), hanya Naqsyabandiah yang silsilah spiritualnya 
sampai ke Nabi Muhammad SAW melalui Abu Bakar Shidiq. Tarekat lain silsilah spiritualnya sampai ke Nabi Muhammad SAW melalui Ali Bin Abi Thalib.

Tarekat Naqsyabandiah adalah tarekat yang paling luas wilayah persebarannya, mulai dari jazirah Arab, Maroko, Eropah Timur wilayah Balkan (Bosnia Herzegovina), India, Malaka, Cina, juga Nusantara yaitu Aceh, Melayu Riau, Banten, Jawa, Kalimantan, Sulawesi, termasuk Muna dan Buton. Tarekat ini berkembang pesat di India pada abad ke 15 M. Masuk di Nusantara pada abad ke 17 M, dibawah oleh Syech Yusus AlMakassari (ia berasal dari Goa namun menetap di Banten karena menikah dengan putri Sultan Banten).

\section{Sepak Terjang La Kokuli Dilihat dari Gelarnya}

Dilihat dari gelar yang disandangnya yaitu Kambera Kakuni 'kupu-kupu kuning', La Kokuli adalah seorang sufi dari golongan Naqsyabadiah. Beliau datang ke Muna dan bermukim di Watuputih guna memperkenalkan Islam di Watuputih dan di wilayah Siua Liwuno lainnya. Harus diakui bahwa proses islamisasi di Nusantara tidak terlepas dari peran para sufi. Islam masuk di Muna pada abd ke -17 di zaman pemerintahan La Ode Abdul Rahman yang bergelar Sangia Latugho (Batoa, 2006). Islam yang masuk di Muna (juga di Buton) tidak berbasis syariat, tetapi berbasis sufisme. Ini akibat yang memperkenalkan Islam pertama kali di Muna (dan di Buton) dari golongan sufi. Masuknya Islam di Muna pada akhir abad ke -17 M seiring dengan masuknya tarekat Naqsyabandiah di Nusantara pada awal abad ke -17 M. Ini berarti bahwa La Kokuli, gelar Kambera Kakuni hidup pada akhir abad ke -17 M.

La Kokuli adalah seorang sufi dan Wali Allah, penganut tassawuf melalui tarekat Naqsyabadiah. Beliau memperkenalkan Islam di Muna pada akhir abad ke-17 M. Beliau juga yang membawa ajaran tarekat Naqsyabandiah di Muna. Ini tersirat dalam gelarnya Kambera Kakuni 'kupu-kupu kuning', lambang tarekat Naqsyabandiah. Statusnya sebagai seorang Wali Allah dibuktikan dengan dua hal, yakni:

(1) Memiliki kelebihan/kesaktian berupa kekebalan, badannya tidak dapat ditembusi benda tajam. Sama halnya dengan Wali Songo yang memperkenalkan Islam di Jawa memiliki kelebihan dan ilmu kesaktian. Masyarakat lokal yang masih menganut kepercayaan animisme dan dinamisme mengagumi mereka sehingga terketuk hatinya untuk mengikuti ajaran baru yang mereka bawa (ajaran Islam).

(2) Wilayah sekitar makamanya adalah keramat (masyarakat Muna menyebutnya popalia). Seorang Wali Allah memiliki karomah. Mengunjungi makam Wali Allah berpotensi mendapatkan percikan karomah 
karena jiwa mereka tetap hidup dan menularkan karomahnya kepada orang yang menziarahi makamnya. Oleh karena itu, wilayah sekitar makam Wali Allah biasanya dihuni oleh mahluk jahat untuk menghindari datangnya masyarakat yang hendak berziarah. Makam La Kokuli dikenal dengan keramatnya (popalia). Sekitar $30 \mathrm{~m}$ dari makamnya ada batu yang menyerupai harimau, masyarakat setempat menyebutnya harimau kontu. Para tetua di Watuputih menuturkan bahwa harimau kontu tersebut memiliki kekuatan jahat dan arah menghadapnya berubah-ubah. Bila menghadap ke arah Barat, kampung di wilayah Barat (Watuputih, Bangkali, Dana, dan sekitarnya) dilanda bencana berupa kelaparan atau wabah penyakit. Bila menghadap ke arah Selatan, maka perkampungan di wilayah Selatan (Rahia, Bungi, Mabodo, dan sekitarnya) juga dilanda bencana berupa kelaparan atau wabah penyakit yang banyak menelan korban. Berdasarkan fenomena tersebut, ada seorang pemuda di Watuputih, bernama Ade Rasa, pada akhir abad ke -20 M mendatangi harimau kontu dan memotong lidahnya dengan menggunakan parang tajam. Alhasil lidah harimau kontu terpotong, namun Ade Rasa meninggal seketika setelah ia pulang dan setibanya di rumah kediamannya. Oleh karena itu, harimau kontu yang berada di puncak BALADEWA saat ini tidak lagi keramat.
Kedatangan Syech Kambera Kakuni di Muna pada akhir abad ke -17 M untuk mengislamkan masyarakat Muna. Beliau masuk di Muna dari arah Barat. Ada dua kemungkinan tempat asalnya, yakni Aceh atau Goa. Bila beliau berasal dari Goa, bisa dipastikan sebagai murid Syech Yusuf AlMakassari. Namun bila berasal dari Aceh, maka ia adalah murid Hamzah Fansuri, atau mungkin juga murid Syamsudin Pasai, atau mungkin juga murid Syech Abdul Rauf Singkil. Bila berasal dari Goa, masyarakat Watuputih memanggilnya Karaeng atau Daeng. Oleh karena itu, kemungkinan besar beliau berasal dari Aceh. Dugaan ini diperkuat dengan penuturan para tetua di Watuputih bahwa pada zaman dahulu ada beberapa tokoh di Watuputih berasal dari Aceh, datang dengan mengendarai sapu tangan. Cerita mengendarai sapu tangan merupakan metode klasik dalam pencitraan seorang tokoh, mirip dengan cerita kedatangan Tandriabeng di Muna dengan mengendarai palangga 'mangkuk besar'. Kemamampuan seorang tokoh yang dikisahkan secara berlebihan dan melampaui batas logika (beyond the logic) bertujuan untuk legitimasi. Ini adalah metode pencitraan pada zaman dahulu sehingga tokoh tersebut dianggap layak menjadi pemimpin. Hani' ah (1999) menyatakan bahwa para pemimpin di Nusantara pada zaman dahulu dicitrakan sebagai sosok supranatural karena 
dikisahkan memiliki kesaktian yang dilebih-lebihkan.

Masyarakat Nusantara di zaman pra Islam secara geografis terdiri atas tiga kelompok. Kelompok pertama masyarakat yang bermukim di wilayah pesisir. Mereka menerima Islam melalui kontak dengan para pedagang dari Arab, India (Gujarat) dan dari Melayu. Para pedagang ini menuju Cina dan singgah di Nusantara untuk membeli rempah-rempah. Nusantara dengan posisinya yang strategis antara India dan Cina merupakan tempat persinggahan para pedagang. Strategi mereka dalam menyiarkan Islam melalui perkawinan dengan wanita-wanita di daerah pantai di Nusantara.

Kelompok kedua adalah masyarakat yang bermukim di pedalaman. Sedangkan kelompok ketiga adalah masyarakat keraton yang bermukim di wilayah pusat kerajaan. Kedua kelompok ini menerima Islam bukan dari para pedagang, tetapi dari para sufi. Daerah Muna walaupun merupakan pulau kecil, namun jauh dari jangkauan pada pedagang Arab, India, dan Melayu. Oleh karena itu, proses islamisasi di Muna merupakan peran para sufi. Menurut sejarah, pembawa Islam di Muna adalah Syech Syarif Muhammad dari Arab pada abad ke -17. Syech Syarif Muhammad disebut juga Syech Arab. Oleh masyarakat Muna disebut Saidhi Raba (disesuaikan dengan cara penyebutan dalam Bahasa
Muna). Akan tetapi, Syech Syarif Muhammad tidak lama di Muna. Di samping itu, sasarannya dalam memperkenalkan Islam di Muna hanyalah masyarakat keraton, tidak sekaligus dengan masyarakat luar keraton (pedalaman). Wa Ode Nur Aini, anak imam Mesjid Kota Wuna (dalam wawancara tanggal 28 Agustus 2015) mengisahkan bahwa Syech Syarif Muhammad menemui Raja Muna La Ode Rahman yang bergelar Sangia Latugho untuk memperkenalkan Islam. Ada syarat yang diberikan oleh Sangia Latugho, apabila permaisurinya bisa hamil berkat doa Syarif Muhammad kepada Allah SWT, ia akan menerima Islam dan menjadikan Islam sebagai agama resmi kerajaan Muna. Berdasarkan persyaratan itu, Syech Syarif Muhammad melaksanakan shalat di hadapan Sangia Latugho sambil bermunajat kepada Allah SWT, memohon agar Wa Ode Sope (Permaisuri Sangia Latugho) dikaruniai anak. Dalam shalatnya ia menghilang, tinggal setetes air yang tampak terlihat. Setelah itu ia muncul kembali, namun seluruh jubahnya basah kuyup. Lalu ia berkata kepada raja sebagai berikut: “Atas izin Allah Azza Wajallah, saya telah meletakkan roh seorang laki-laki dalam rahim permaisuri Tuan Raja; saya berpesan agar pada saat dia lahir nanti, berilah dia nama Husein". Setelah mengucapkan katakata itu, Syech Syarif Muhammad menghilang. Tidak lama kemudian, 
permaisuri Sangia Latugho (Wa Ode Sope)

hamil. Setelah lahir, anaknya laki-laki dan diberi nama La Ode Husein.

Secara teoretis dan ilmu kedokteran, Wa Ode Sope tidak mungkin bisa hamil karena pada saat menikah dengan Sangia Latugho telah berusa lanjut (mono pause). La Ode Ongga (1999) menyatakan bahwa Wa Ode Sope adalah mantan kekasih ayah Sangia Latugho, yaitu Sangia Kaendea. Setelah Sangia Latugho dilantik menjadi Raja Muna menggantikan ayahnya, sang ayah berpesan agar menikahi wanita mantan kekasihnya yang gagal dinikahinya. Wanita dimaksud adalah Wa Ode Sope, putri La Ode Arafani Sapati Baaluwu Buton. Pesan ini diindahkan oleh Sangia Latugho sehingga ia menikahi Wa Ode Sope yang saat itu telah berusia lanjut (mono pause). Aderlaepe (2017: 267-268) menyatakan bahwa Sangia Latugho bersedia menikahi Wa Ode Sope walaupun telah berusia lanjut sebagai strategi untuk memulihkan hubungan Muna dan Buton yang sebelumnya retak. Sebelum Sangia Latugho menjadi Raja Muna, terjadi perang di Selat Buton antara Goa melawan Buton pada tahun 1667. Di satu pihak, Buton dibantu oleh Ternate, Belanda, dan Bone; sedangkan di pihak lain, Goa dibantu oleh Muna dan Tiworo (Batoa, 2003). Perang itu berakhir dengan kemenangan di pihak Buton dan Sultan Hasanuddin, Raja Goa, ditangkap oleh Belanda (Nasrun, 1988:51).
Menurut sejarah, pembawa Islam di Muna adalah Syech Syarif Muhammad alias Syech Arab (Saidhi Raba) pada abad ke -17 M. Namun perlu dicatat bahwa Syech Syarif Muhammad tidak lama di Muna dan sasaran siar Islam yang ia lakukan adalah masyarakat keraton. Adapun proses islamisasi masyarakat Muna di luar keraton (kelompok masyarakat pedalaman) menjadi wilayah kerja $\mathrm{La}$ Kokuli, Syech Kambera Kakuni. La Kokuli berdiam di Watuputih, memperkenalkan Islam pada masyarakat Watuputih dan masyarakat di Siua Liwuno (Sembilan kampung). Tidak hanya di Watuputih dan di Siua Liwuno, beliau juga menyiarkan Islam di wilayah Muna lainnya.

Teori A.H. Johns bahwa Islam masuk ke Indonesia melalui para sufi pengembara. Merekalah yang lebih berhasil mengislamkan Nusantara. Penyiaran Islam di Nusantara dilakukan melalui empat strategi, yaitu (1) metode perdagangan, (2) pendekatan perkawinan, (3) pendekatan politik, dan (4) metode sufistik. Amnan (2015) menegaskan bahwa metode sufistiklah yang paling mendominasi dalam proses islamisasi di Nusantara.

\subsection{Ajaran Martabat Tujuh sebagai Produk Sufi}

Peran para sufi dala proses islamisasi di Nusantara dapat dilihat dari kemiripan antara ajaran sufisme dengan kebudayaan Nusantara pada zaman pra Islam. 
Akulturasi budaya lokal dengan ajaran Islam nampak saling bersimbiosis demi berkembangnya siar Islam. Sebagai contoh di daerah Muna, Wambano Toba (nasehat pemuka agama pada saat upacara katoba, yaitu upacara pengislaman anak yang telah mencapai usia baliq/dewasa) mirip dengan Martabat Tujuh ajaran Naqsyabandiah. Bagi Naqsyabandii (pengikut Naqsyabandiah), tingkat maqam ada tujuh, dikenal dengan nama Martabat Tujuh. Maqam yang dimaksud di sini adalah tempat, kedudukan, atau derajat seseorang dalam bertawajjuh kepada Allah (zikir menuju atau mencapai Allah SWT). Seseorang yang bertawajjuh merasakan sendiri dan mengevaluasi dirinya sendiri tingkatan yang dicapainya. Ketujuh tingkatan itu adalah: (1) taubat; (2) sabar; (3) syukur; (4) khauf (takut hanya kepada Allah SWT); (5) ridha; (6) muhibbah (cinta kepada Allah SWT); dan (7) hakikat.

Pada tingkat pertama yaitu taubat, seseorang harus melakukan zuhud. Ada tiga jabaran pelaksanaan zuhud dalam ajaran Naqsyabandiah yaitu:

(1) Menyesali perbuatan dosa yang telah dilakukan

(2) Menghentikan segala perbuatan dosa yang pernah dilakukan

(3) Berjanji dan menetapkan dalam hati bahwa segala perbuatan dosa tidak akan dilakukan lagi.
(4) Menjauhkan diri dari segala potensi yang dapat menjerumskan diri dalam perbuatan perbuatan dosa.

Bila dicermati dengan seksama, jabaran zuhud pada maqam tingkat pertama (taubat) sama dengan prinsip toba 'taubat' dalam upacara katoba (upacara pengislaman anak saat memasuki usia baliq di Muna).

Otoba kaengkoarahano didima; popaa maighono ne manusia, seise maighono ne Allah Ta Allah. Maighoono ne manusia o soso, bhotuki, tindaki, fekakodoho. Maighoono ne Allah Ta Allah hakunaasi

" Taubat didasari oleh lima perkara; empat berasal dari manusia dan satu berasal dari Allah SWT. Yang berasal dari manusia adalah penyesalan (ososo), penghentian perbuatan dosa (bhotuki), ketetapan tidak mengulangi lagi perbuatan dosa (tindaki), dan menjauhkan diri dari perbuatan dosa (fekakodoho). Yang berasal dari Allah SWT adalah hak naas (mengambil/mamakan sesuatu yang bukan hak)".

Martabat Tujuh di Buton dan di Muna dijadikan sebagai kitab undang-undang negeri. Masyarakat Buton mengklaim bahwa Martabat Tujuh adalah karya fenomenal Sultan Buton Dayanu Ikhsanuddin pada abad ke -17 M. Anggapan ini keliru, karena ajaran Martabat Tujuh pertama kali dikemukakan oleh seorang sufi India padaabad ke -15 M, bernama Muhammad Ibnu Fadhilah dalam kitab yang ditulisnya berjudul $A l$ Tuhfah $A l$ Mursalah ila Ruhin-Nabi. Dalam menulis ajaran martabat tujuh, Ibnu Fadhilah 
dipengaruhi oleh pemikiran Ibnu Arabi, seorang sufi kelahiran Meurcia Spanyol. Martabat Tujuh merupakan ajaran tassawuf yang berintikan pengenalan kepada Allah SWT. Menurut Ibnu Fadhilah, Tuhan merupakan wujud mutlak, tidak dapat dipersepsi oleh akal, perasaan, khayal, apalagi indera. Untuk bisa memahami keberadaan Tuhan yang sebenarnya, seseorang harus bertajalli sejumlah tujuh martabat, yang dikenal dengan Martabat Tujuh.

Dalam perkembanganya di Nusantara, ajaran Martabat Tujuh berkembang di Aceh. Tiga tokoh utma yang mengembangkannya adalah Hamzah Fansuri, Samsudin Pasai, dan Abdul Rauf. Di Buton ajaran Martabat Tujuh diadopsi dan diadaptasi lalu dijadikan sebagai Kitab Undang-Undang Kesultanan Buton. Untuk bisa beribadah kepada Allah SWT, terlebih dahulu harus mengenal-Nya. Menurut ajaran ini, Allah SWT memperkenlakna dirinya melalui tujuh martabat, yaitu: (1) Martabat Ahadiyat, (2) Martabat Wahdat, (3) Martabat Wahidiyat, (4) Alam Arwah, (5) Alam Mitsal, (6) Alam Ajsam, dan (7) Alam Insan Kamil. Selain itu, Martabat Tujuh menurut Undang-Undang Kesultanan Buton merupakan perwujudan tujuh pemimpin negeri, yaitu (1) Sultan, (2) Sapati, (3) Kinepulu, (4) Lakina Muna, (5) Lakina Kulisusu, (6) Lakina Kaledupa, dan (7) Lakina Tobe-tobe. Di Muna, ketujuh pemimpin negeri yang disimbolkan dengan Martabat Tujuh adalah (1) Omputo 'raja', (2) Bhonto Bhalano, (3) Meintarano Bhitara, (4) Koghoerano Tongkuno, (5) Koghoerano Lawa, (6) Koghoerano Kabawo, dan (7) Koghoerano Katobu.

Penulis menduga bahwa ajaran Martabat Tujuh yang ada di Buton dan di Muna dibawa dari Aceh. Pada abad ke -17, ajaran ini dibawah oleh Syech Kambera Kakuni dari Aceh. Syech Kambera Kakuni adalah murid Abdur Rauf Singkil (bergelar Teungku Syiah Kuala), seorang ulama besar Aceh yang berpengaruh dalam penyebaran Islam di Nusanatara pada abad ke -17 .

\section{KESIMPULAN}

Melalui uraian yang dikemukakan di atas, penulis menyimpulkan beberapa hal sebagai berikut:

(1) La Kokuli yang bergelar Kambera Kakuni (penulis cenderung menyebutnya Syech Kambera Kakuni) adalah seorang sufi Wali Allah dari kelompok Naqsyabandiah. Kambera kakuni 'kupu-kupu kuning adalah lambang tarekat Naqsyabandiah.

(2) Syech Kambera Kakuni bukan penduduk asli Muna, tetapi pendatang dari Aceh. Beliau hidup pada akhir abad ke -17 dan awal abad ke -18 . Kedatangannya di Muna guna menyiarkan Islam. Beliau bermukim di Watuputih dan menyiarkan Islam di 
Siua Liwuno: Watuputih, Bungi, Mabodo, Kontu Naga, Lambiku, Duruka, Masalili, Mantobua, Lohia, dan Mabolu. Di samping itu, beliau juga menyiarkan Islam di wilayah Muna lainnya di luar Siua Liwuno.

(3) Syech Kambera Kakuni bukan hanya pembawa Islam di Muna pada masyarakat luar keraton, tetapi juga sebagai pembawa ajaran Martabat Tujuh di Muna (dan di Buton). Pada abd ke -17, ajaran Martabat Tujuh di Buton dan di Muna diadopsi dan diadaptasi serta dijadikan sebagai Undang-Undang negeri. Ajaran Martabat Tujuh sebelumnya berkembang pesat di Aceh dengan tokohnya yang terkenal, yaitu Syech Abdul Rauf, bergelar Syech Teungku Syiah Kuala. Syech Kambera Kakuni adalah murid Syech Teungku Syiah Kuala

\section{DAFTAR PUSTAKA}

Aderlaepe. 2017. Sejarah dan Kebudayaan Muna. Jakarta: Daulat Press

Amnan, Dzulkifli. 2015. "Tasawuf dan Tarekat di Aceh: Tokoh-Tokoh dan Ajarannya" http://dzulkifliamnan87. Wordpress.Co

Batoa, La Kimi. 2003. Profil Raja La Ode Kadiri, Gelar Sangia Kaindea, Raja
Muna XII. Raha: Dinas Pendidikan Nasional Kabupaten Muna

Batoa, La Kimi. 2006. Profil Raja La Ode Abdul Rahman (Gelar Sangia La Tungho). Raha: Dinas Pendidikan Nasional Kabupaten Muna

Danandjaja, James. 1997. Folklore Indonesia: Ilmu Gosip, Dongeng, dan lain-lain. Jakarta: Graffiti.

Hani'ah. 1999. Parodi Menggugat Tradisi: $\quad$ Makalah yang Disampaikan dalam Suara-Suara Milenium, Dialog Antarbudaya. Jakarta: Asosiasi Tradisi Lisan.

Hoed, Benny H., 2011. Semiotik dan Dinamika Sosial Budaya. Jakarta: Komunitas Bambu

La Ode Ongga. 1999. Kebangkitan dan Sinar Islam di Sulawesi Tenggara. Saduran dari Naskah-Naskah yang Tersimpan di Daerah Muna dan Buton

Lord, Albert B., 1995. The Singer Resumes the Tale. Edited by Mary Louisi Lord. Ithaca: Cornell University Press.

Nasrun, Muhammad. 1988. Kerajaan Muna dan Sistem Kemasyarakatan. Bandung: Penerbit Indah Jaya

Ong, Walter J. 1982. Orality and Literacy. New York: Methuen.

Pierce, C.S. (1965) Collected Papers, vols I, II. Cambridge: Harvard University Press

Pudentia, 2010. "The Revitalization of Mak Yong in the Malay World", Jurnal Wacana, Volume 12, Nomor 1, Halaman 1-19.

Rahman, Nurhayati. 1999. Antologi Sastra Daerah Nusantara, Cerita Rakyat Suara Rakyat. Jakarta: Yayasan Obor Indonesia 